\title{
Detection and characterization of Cryptosporidium species and genotypes in three chicken production systems in Brazil using different molecular diagnosis protocols
}

\author{
Bruna Nicoleti Santana ${ }^{\mathrm{a}}$, Brayan Kurahara ${ }^{\mathrm{a}}$, Alex Akira Nakamura ${ }^{\mathrm{b}}$, Vinícius da Silva Camargo ${ }^{\mathrm{a}}$, \\ Elis Domingos Ferrari ${ }^{a}$, Giane Serafim da Silva ${ }^{c}$, Walter Bertequini Nagata ${ }^{a}$, \\ Marcelo Vasconcelos Meireles ${ }^{\mathrm{a} \text {,* }}$ \\ a Universidade Estadual Paulista (Unesp), Faculdade de Medicina Veterinária, Araçatuba, Rua Clóvis Pestana, 793, CEP 16050-680, Bairro Dona Amélia, Araçatuba, SP, \\ Brazil \\ ${ }^{\mathrm{b}}$ Faculdades Adamantinenses Integradas (FAI), Adamantina, Brazil \\ ${ }^{\mathrm{c}}$ Instituto Biológico, Agência Paulista de Tecnologia Agropecuária, Votuporanga, Brazil
}

\section{A R T I C L E I N F O}

\section{Keywords:}

Cryptosporidiosis

Diagnosis

Molecular characterization

Domestic chicken

Brazil

\begin{abstract}
A B S T R A C T
The objective of this study was to determine the occurrence of Cryptosporidium spp. in domestic chickens raised in different chicken production systems in Brazil using three nested PCR protocols. The purification and concentration of oocysts present in 190 fecal samples from chickens raised in extensive, semi-intensive and intensive production systems were accomplished by centrifugal flotation in Sheather's solution and were followed by the extraction of genomic DNA. The detection and molecular characterization of Cryptosporidium species and genotypes were performed using three nested polymerase chain reaction (nested PCR) protocols targeting the 18S rRNA gene followed by sequencing of the amplified fragments. Subgenotyping of $C$. meleagridis was performed using a nested PCR reaction targeting the gp60 gene. Sample identified as Cryptosporidium sp. genetically similar to Cryptosporidium xiaoi and Cryptosporidium bovis by $18 \mathrm{~S}$ rRNA gene sequencing were further analyzed by nested PCR targeting the actin gene and subsequent sequencing of the amplified fragment. Positive amplification for Cryptosporidium spp. was observed in 12.6\% (24/190) of the samples, including C. baileyi (9.8\%; 18/190), C. meleagridis $(0.5 \%, 1 / 190)$, C. parvum $(2.1 \% ; 4 / 190)$ and Cryptosporidium sp. $(0.5 \% ; 1 / 190)$. Subgenotyping of $C$. meleagridis revealed the presence of the zoonotic subtype IIIgA23G3R1. Sequencing of the 18S rRNA gene and the actin gene fragments revealed a Cryptosporidium genotype in an extensive poultry system genetically related to $C$. xiaoi and $C$. bovis. There was no significant difference in the frequency of positive results obtained by the three nested PCR protocols ( $\mathrm{p}>0.05$ ); additionally, the agreement obtained by Kappa index ranged from substantial (0.70) to almost perfect (0.9).
\end{abstract}

\section{Introduction}

Cryptosporidiosis is one of the most prevalent protozoan infections in birds, and it manifests as a respiratory or digestive disease (Ryan, 2010; Nakamura and Meireles, 2015). Among the 31 species of Cryptosporidium that infect several vertebrates, only four infect birds: $C$. meleagridis, C. baileyi, C. galli and C. avium (previously known as avian genotype V) (Holubová et al., 2016; Ryan et al., 2016).

In addition to these species, there are descriptions of the Cryptosporidium avian genotypes I (Ng et al., 2006), II (Santos et al., 2005; Meireles et al., 2006; Ng et al., 2006), III (Ng et al., 2006), IV (Ng et al., 2006), VI (Chelladurai et al., 2016), VII, VIII and IX (Helmy et al.,
2017), the goose genotypes I-IV (Jellison et al., 2004; Zhou et al., 2004), the black duck genotype (Morgan et al., 2001) and the Eurasian woodcock genotype (Ryan et al., 2003) infecting birds.

The literature related to the occurrence of Cryptosporidium infection in avian species is scarce, most likely because the techniques used to diagnose cryptosporidiosis are not routinely adopted in avian pathology laboratories. Infections by $C$. baileyi, $C$. galli, and other avian Cryptosporidium species/genotypes are present in a wide variety of bird species; in contrast, C. meleagridis has a more restricted number of avian hosts (Sréter and Varga, 2000; Ng et al., 2006; Qi et al., 2011; Nakamura and Meireles, 2015). There is only one report of $C$. parvum infection associated with clinical signs in birds (Zylan et al., 2008).

\footnotetext{
* Corresponding author.

E-mail address: marcelo@fmva.unesp.br (M.V. Meireles).
} 
Table 1

Nested PCR protocols used for the detection of Cryptosporidium spp. in domestic chicken fecal samples.

\begin{tabular}{|c|c|c|c|c|}
\hline Protocols & & Primers $5^{\prime}-3^{\prime}$ sequences & Amplified product (bp) & References \\
\hline \multirow[t]{2}{*}{ Protocol 1} & PCR & $\begin{array}{l}\text { GGAAGGGTTGTATTTATTAGATAAAG } \\
\text { CTCATAAGGTGCTGAAGGAGTA }\end{array}$ & $\sim 848$ & $\begin{array}{l}\text { Xiao et al. (1999) } \\
\text { Jiang et al. (2005) }\end{array}$ \\
\hline & Nested PCR & $\begin{array}{l}\text { AAGCTCGTAGTTGGATTTCTG } \\
\text { TAAGGTGCTGAAGGAGTAAGG }\end{array}$ & $\sim 425$ & Johnson et al. (1995) \\
\hline \multirow[t]{2}{*}{ Protocol 2} & PCR & $\begin{array}{l}\text { GACATATCATTCAAGTTTCTGACC } \\
\text { CTGAAGGAGTAAGGAACAACC }\end{array}$ & $\sim 761$ & Ryan et al. (2003) \\
\hline & Nested PCR & $\begin{array}{l}\text { CCTATCAGCTTTAGACGGTAGG } \\
\text { TCTAAGAATTTCACCTCTGACTG }\end{array}$ & $\sim 585$ & \\
\hline \multirow[t]{2}{*}{ Protocol 3} & PCR & $\begin{array}{l}\text { TTCTAGAGCTAATACATGCG } \\
\text { CCCATTTCCTTCGAAACAGGA }\end{array}$ & $\sim 1318$ & Xiao et al. $(1999,2000)$ \\
\hline & Nested PCR & $\begin{array}{l}\text { GGAAGGGTTGTATTTATTAGATAAAG } \\
\text { AAGGAGTAAGGAACAACCTCCA }\end{array}$ & $\sim 835$ & \\
\hline
\end{tabular}

Most reports of cryptosporidiosis in domestic chickens are related to C. baileyi, which infects the respiratory tract, bursa of Fabricius and cloaca (Current et al., 1986), and less frequently to C. meleagridis, which is restricted to the small intestine (Sréter and Varga, 2000). C. galli and C. avium, as well as the avian genotypes of Cryptosporidium, are rarely described in domestic chickens (Nakamura and Meireles, 2015).

The importance of cryptosporidiosis in domestic chickens is unclear. Snyder et al. (1988) reported that the prevalence of antibodies to Cryptosporidium sp. in broiler chickens was $24 \%$ per flock in 18 flocks. Infection with $C$. baileyi in broiler chickens has been related to decreased weight gain, higher incidence of airsacculitis, increased mortality, and higher carcass condemnation rates in slaughterhouses (Gorham et al., 1987; Goodwin et al., 1996). C. meleagridis infection in domestic chickens is asymptomatic (Nakamura and Meireles, 2015).

In Brazil, there have been several reports of natural infection by $C$. baileyi in chickens (Meireles and Figueiredo, 1992; Huber et al., 2007). Using experimental infection with a Brazilian isolate of $C$. baileyi, Meireles et al. (1998a, b, 1999) found that domestic chickens developed clinical signs and macroscopic lesions related to the respiratory tract, as well as macroscopic lesions in the bursa of Fabricius.

C. meleagridis is a parasite of the intestinal epithelial cells in several species of birds, particularly turkeys (Slavin, 1955; Sréter and Varga, 2000), and it is the only avian species of Cryptosporidium with zoonotic potential (Chalmers and Giles, 2010). In some countries, the occurrence of $C$. meleagridis infection in humans is similar or superior to that of $C$. parvum infections (Xiao et al., 2001; Cama et al., 2003). In Brazil, C. meleagridis has been found in fecal samples from domestic chickens (Huber et al., 2007; Nakamura et al., 2009) and humans (Araújo et al., 2008).

Cryptosporidium species can be identified using molecular methods, such as polymerase chain reaction (PCR), followed by sequencing of the amplified fragments. The most commonly used protocol is nested PCR targeting the 18S rRNA gene, developed by Xiao et al. (1999, 2000). However, Mirhashemi et al. (2015) compared three nested PCR protocols using equine, bovine and ovine samples and found that the protocol developed by Ryan et al. (2003) was the most sensitive. There are no studies on the effectiveness of different molecular diagnostic techniques for the detection of Cryptosporidium spp. in avian fecal samples.

Also, there are few studies related to the prevalence of Cryptosporidium spp. in chickens from extensive, semi-intensive and intensive production systems (Nakamura and Meireles, 2015). In addition to presenting clinical disease when infected with Cryptosporidium, domestic chickens may be a source of infection of zoonotic species of this protozoan, such as C. meleagridis and Cryptosporidium species and genotypes adapted to mammals. The present work aimed to determine the occurrence of Cryptosporidium spp. in domestic chickens raised in different production systems and to perform molecular characterization of Cryptosporidium spp. using three nested PCR protocols and sequencing of the amplified fragments.

\section{Material and methods}

\subsection{Fecal samples}

This study was approved by the Animal Use Ethics Committee (CEUA) of the São Paulo State University (Unesp), School of Veterinary Medicine, Araçatuba, process FOA 2015-00572.

Fecal samples were obtained from domestic chickens (Gallus gallus domesticus) in 20 municipalities of the State of São Paulo, Brazil. According to availability, the samples were collected in 61 chicken farms with extensive (24), semi-intensive (8), intensive-layers (25), and intensive-broilers (4) production systems. Mixed types of chickens (broilers and layers) were raised in farms with extensive and semi-intensive production systems. Samples consisted of 190 fecal pools (each containing $10-20 \mathrm{~g}$ of feces) formed from the collection of up to 5-10 single fecal droppings per farm with extensive and semi-intensive production systems. In intensive production systems, one fecal pool was collected from up to four flocks.

In the extensive poultry production systems, it was not possible to identify the age of the birds at the time of collection. In the semi-intensive and intensive-layers production systems, the birds were all adults or were 8-16 weeks old, respectively. Broiler chickens from intensive production systems were 35-46 days old.

The samples consisted of freshly discarded feces collected using a disposable wooden spatula and were preserved in $2.5 \%$ potassium dichromate at $4{ }^{\circ} \mathrm{C}$. The concentration and purification of oocysts were performed by centrifugal-flotation using Sheather's sugar flotation solution.

\subsection{Molecular characterization}

Genomic DNA from oocysts was extracted from purified fecal sediment (Boom et al., 1990; McLauchlin et al., 2000). Three nested PCR protocols targeting the 18S rRNA gene were used for the detection of Cryptosporidium spp. (Table 1). Samples that were identified as C. meleagridis and Cryptosporidium sp. by sequencing of the 18S rRNA amplicons were subjected to nested PCR targeting the gp60 gene (Stensvold et al., 2014) or the actin gene (Sulaiman et al., 2002), respectively. Genomic DNA from C. parvum and ultrapure water were used as positive and negative controls, respectively.

\subsection{DNA sequence analysis}

The nested PCR amplicons were purified using the Illustra ExoProStar 1-Step (GE Healthcare Life Sciences) or the QIAquick ${ }^{\circ}$ Gel Extraction Kit (Qiagen), following the manufacturer's guidelines. Sequencing was accomplished using the ABI Prism ${ }^{\circledR}$ Dye Terminator Cycling Sequence kit (Applied Biosystems) in an Automatic sequencer ABI 3730XL (Applied Biosystems).

DNA sequences were assembled with Codoncode Aligner version 
7.1.1 software (CodonCode Corporation). The consensus sequences were aligned with homologous sequences published in GenBank using Clustal W (Thompson et al., 1997) and BioEdit Sequence Alignment Editor (Hall, 1999). Phylogenetic trees were generated using Maximum Likelihood analysis based on the General Time Reversible model (Nei and Kumar, 2000) in MEGA7 (Kumar et al., 2016) using Cryptosporidium molnari as an outgroup.

\subsection{Nucleotide sequence accession number}

Nucleotide sequences generated in this study were submitted to the GenBank database under the accession numbers MF627416 through MF627421.

\subsection{Statistical analysis}

Statistical analysis was performed using Microsoft Office Excel 2010, and results were considered significant when $\mathrm{p}<0.05$. Frequency analysis (McNemar test) and the Kappa correlation coefficient (Landis and Koch, 1977) were calculated to verify the difference in positive rates between each paired nested PCR protocols and the agreement between the diagnostic methods, respectively. Prevalence rates with $95 \%$ confidence intervals were calculated using Wilson (score) intervals (Sergeant, 2017).

\section{Results}

The frequency of positive Cryptosporidium spp. detection by the three nested PCR protocols was 24/190 (12.6\%; 95\% confidence interval: 8.6-18.1\%). Sequencing of the $18 \mathrm{~S}$ rRNA amplicons identified $C$. baileyi (9.5\%; 18/190), C. meleagridis $(0.5 \% ; 1 / 190)$, C. parvum $(2.1 \%$; 4/190) and Cryptosporidium sp. (1/190). The sequences from C. baileyi, C. meleagridis and C. parvum had $100 \%$ genetic similarity with sequences previously published in GenBank (AJ276096, AF112574, AF093490). The sequence from Cryptosporidium sp. had 100\% genetic similarity with a sequence from environmental Cryptosporidium sp. (EU825742) (Yang et al., 2008).

Two out of four valid Cryptosporidium species from birds, in addition to C. parvum and Cryptosporidium sp., were identified in farms with different production systems (Table 2). In farms with extensive systems, C. parvum $(16.7 \%$; 4/24), C. baileyi $(4.2 \% ; 1 / 24)$, and Cryptosporidium sp. $(4.2 \% ; 1 / 24)$ were identified. In the semi-intensive systems, $25 \%$ of farms $(2 / 8)$ were positive for $C$. baileyi. In the intensive systems (layers and broilers), $51.7 \%$ of farms (15/29) were positive for C. baileyi, and $3.4 \%$ of farms $(1 / 29)$ were positive for $C$. meleagridis.

Statistical analyses related to variables type of chickens, production systems or Cryptosporidium species were not performed, since the convenience sampling adopted in our study resulted in small and very different sample sizes, among production systems and chicken types, to provide the statistical power required to detect a meaningful difference between study variables. Moreover, any statistically significant difference would be of very little use owing to the wide confidence intervals (Table 2).

GP60 subgenotyping of $C$. meleagridis revealed the zoonotic subtype IIIgA23G3R1. Ribosomal RNA gene sequence from Cryptosporidium sp. found in an extensive production system has already been described in an environmental sample (Yang et al., 2008). Here, we designated this genotype as Cryptosporidium xiaoi-like, owing to its genetic similarity at the actin gene with C. xiaoi (GQ337964) and C. bovis (AY741307) of $96 \%$ and $95 \%$, respectively. At the $18 \mathrm{~S}$ rRNA gene, C. xiaoi-like presented genetic similarity with C. xiaoi (FJ896043) and Cryptosporidium bovis (DQ871346) of 99\% and 99\%, respectively, and it clustered in a separate clade from those two species in the phylogenetic tree (Fig. 1).

The results from the McNemar test showed no significant differences in the number of samples diagnosed as positive for Cryptosporidium spp. among the three nested PCR protocols (Table 3): protocols 1 and 2 $(\mathrm{p}=0.3438), 1$ and $3(\mathrm{p}=0.1797)$ and 2 and $3(\mathrm{p}=1)$. The agreement obtained by Kappa correlation coefficient ranged from substantial to almost perfect: protocols 1 and 2 (0.70), 1 and $3(0.74)$ and 2 and 3 (0.90).

\section{Discussion}

In the present study, the two most frequently reported species in Galliformes, C. baileyi and C. meleagridis, were identified in domestic chickens. Although there have been reports in Brazil concerning the occurrence of $C$. baileyi in domestic chickens (Meireles and Figueiredo, 1992; Cardozo et al., 2005; Nakamura et al., 2009), this is the first report of molecular identification in chickens reared under extensive, semi-intensive and intensive production systems in Brazil.

In Brazil, C. parvum has been found in fecal samples from Nymphicus hollandicus (Nakamura et al., 2009), G. g. domesticus, Coturnix coturnix japonica (Bomfim et al., 2013), Lonchura striata domestica (Gomes et al., 2012) and Columba livia (Oliveira et al., 2017). C. parvum is not a major cause of disease in birds, although there are many reports of detection of $C$. parvum DNA in fecal samples of asymptomatic birds from several avian species (Nakamura et al., 2009; Reboredo-Fernández et al., 2015; Helmy et al., 2017; Oliveira et al., 2017). The detection of $C$. parvum, the most frequent species found in ruminants, and $C$. xiaoi-like suggests that chickens, in both cases, were probably mechanical carriers of oocysts (Majewska et al., 2009), since they were raised in extensive production systems and cohabited with cattle. However, C. parvum has also been detected in fecal samples from chickens and turkeys raised under intensive production systems with no previous contact with fecal samples from mammals (Helmy et al., 2017), which raises concern that poultry could act as a source of infection of other zoonotic Cryptosporidium species, in addition to $C$. meleagridis.

The low rate of detection of $C$. meleagridis corroborated the results of Wang et al. (2014) who reported a prevalence of 5.3\% (2/38) for $C$. meleagridis infection in domestic chickens in China. However, Laatamna et al. (2017) found a prevalence of $35.5 \%$ (11/31) for $C$. meleagridis in domestic chickens in Algeria. In Brazil, C. meleagridis has been

Table 2

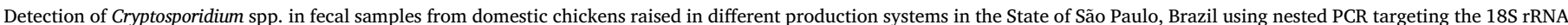
gene and the subsequent sequencing of amplified fragments.

\begin{tabular}{|c|c|c|}
\hline Production system & $\mathrm{N}^{\circ}$ positive farms $/ \mathrm{n}^{\circ}$ sampled (\% positive; $95 \% \mathrm{CI}^{*}$ ) & Species identification $-\mathrm{n}^{\circ}$ positive farms $/ \mathrm{n}^{\circ}$ sampled (\% positive; $95 \% \mathrm{CI}$ ) \\
\hline \multirow[t]{3}{*}{ Extensive } & $6 / 24(25 ; 12-44.9 \%)$ & C. parvum - 4/24 (16.7; 6.9-35.8\%) \\
\hline & & C. baileyi $-1 / 24(4.2 ; 0.7-20.2 \%)$ \\
\hline & & C. xiaoi-like - $1 / 24$ (4.2; 0.7-20.2\%) \\
\hline Semi-intensive & $2 / 8(25 ; 7.2-59.1 \%)$ & C. baileyi - 2/8 (25; 7.15-59.1\%) \\
\hline \multirow[t]{2}{*}{ Intensive-layers } & $15 / 25(60 ; 40.7-76.6 \%)$ & C. baileyi - 14/25 (51.7; 37.1-73.3) \\
\hline & & C. meleagridis $-1 / 25$ (3.4; 0.7-19.5) \\
\hline Intensive-broilers & $1 / 4(25 ; 4.6-69.9 \%)$ & C. baileyi $1 / 4-(25 ; 4.6-69.9)$ \\
\hline Total & $24 / 61(39.3 ; 28.0-51.8 \%)$ & \\
\hline
\end{tabular}

* 95\% Confidence Interval. 


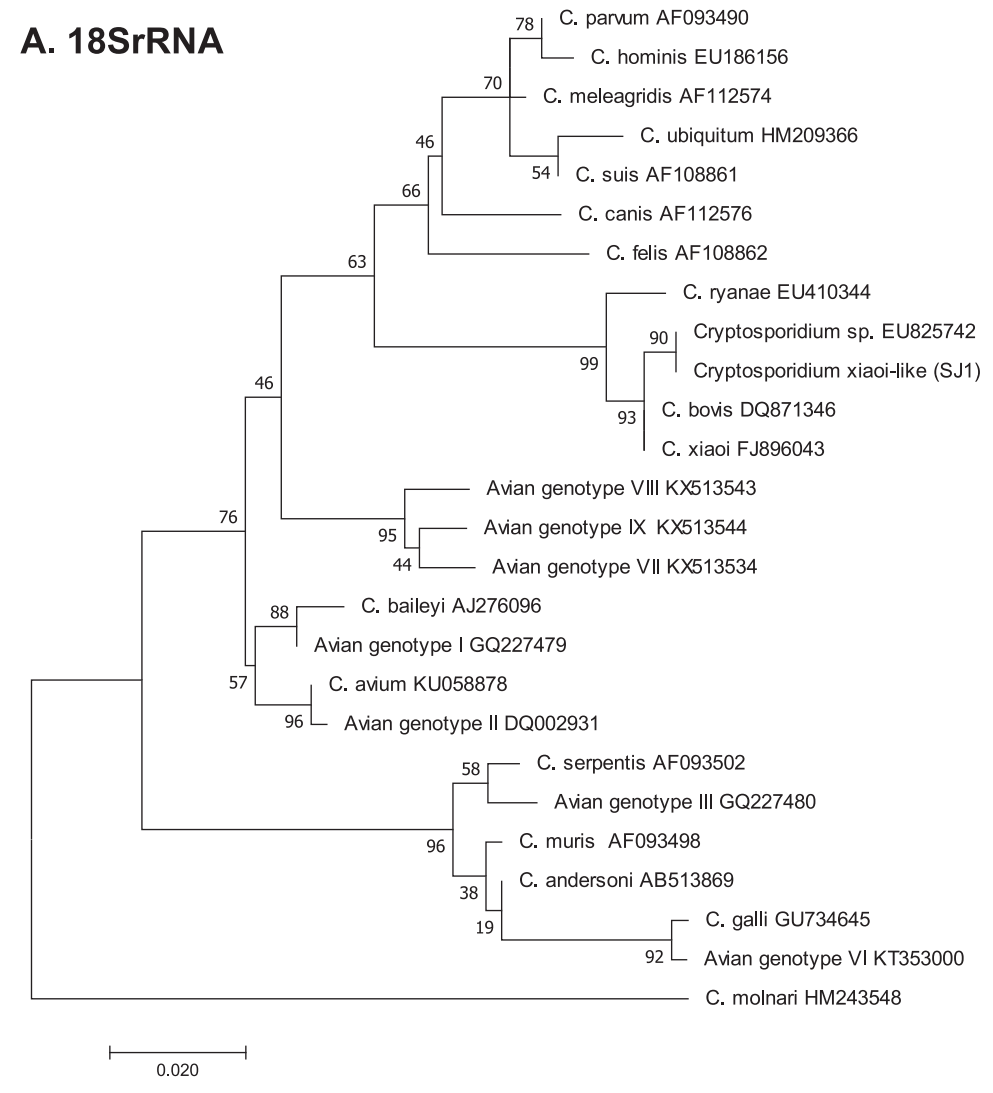

Fig. 1. Phylogenetic trees of the 18SrRNA (A) and actin (B) genes sequences (477 and 721 base positions in the final 18S rRNA and actin datasets, respectively) from Cryptosporidium xiaoi-like (SJ1) and selected Cryptosporidium species. The evolutionary history was inferred by a Maximum Likelihood analysis based on the General Time Reversible model (Nei and Kumar, 2000). The tree with the highest log-likelihood is shown. Initial tree(s) for the heuristic search were obtained automatically by applying Neighbor-Join and BioNJ algorithms to a matrix of pairwise distances estimated using the Maximum Composite Likelihood (MCL) approach and then selecting the topology with superior log-likelihood value. The trees were rooted with sequences from Cryptosporidium molnari. Numbers on the left of the supported nodes indicate the bootstrap values (1000 replicates). Scale-bar represents the number of substitutions per site. Evolutionary analyses were conducted in MEGA7 (Kumar et al., 2016).

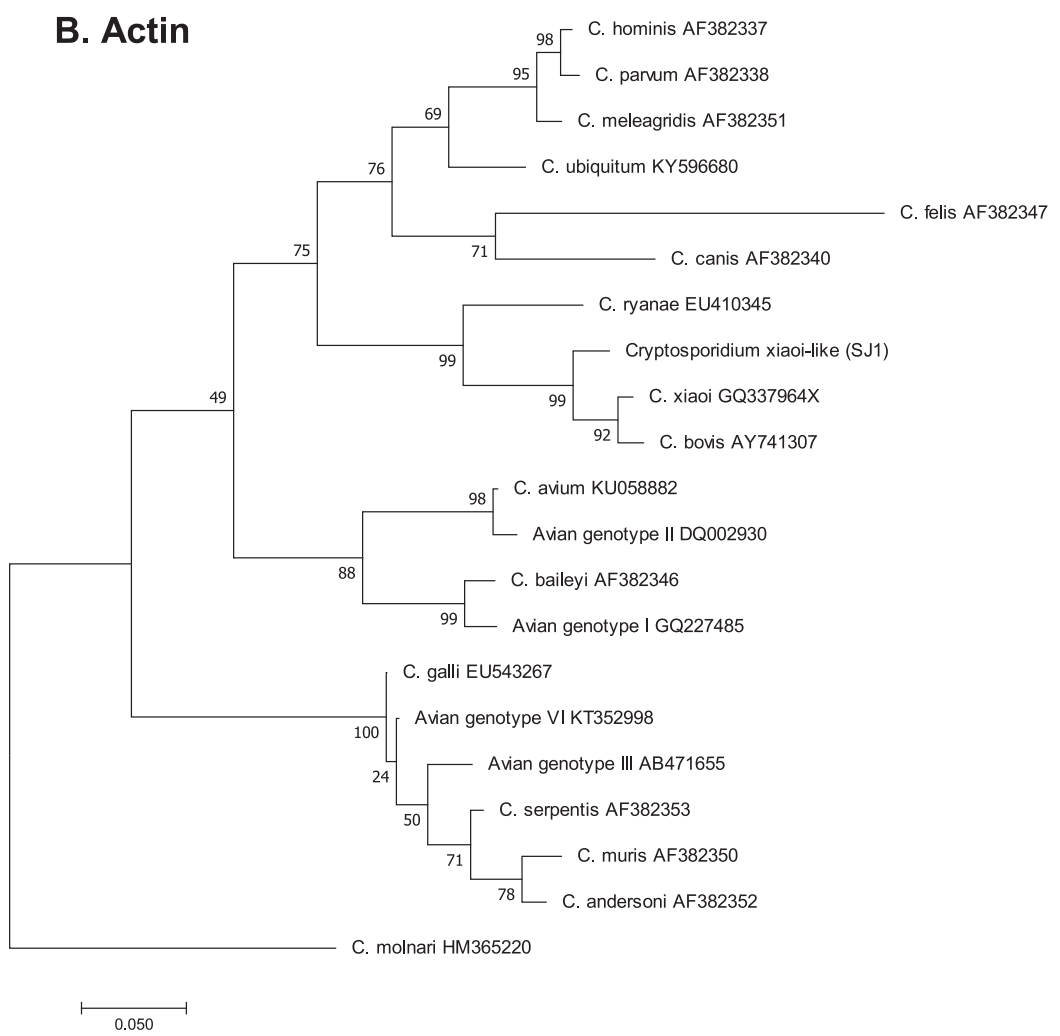

described in domestic chickens (Huber et al., 2007; Nakamura et al., 2009) and in humans (Araújo et al., 2008).

C. meleagridis is an important zoonotic species that infects the intestinal epithelial cells in both birds and mammals (Chalmers and Gilles, 2010). GP60 subgenotyping demonstrated that the $C$. meleagridis subgenotype described in this report, which was previously detected 
Table 3

Identification of Cryptosporidium spp. in fecal samples from domestic chickens using three nested PCR protocols targeting the 18S rRNA gene followed by the sequencing of the amplified fragments.

\begin{tabular}{|c|c|c|c|}
\hline \multirow[t]{2}{*}{ Sample } & \multicolumn{3}{|c|}{ Species identification } \\
\hline & Protocol 1 & Protocol 2 & Protocol 3 \\
\hline SJ1 & - & Cryptosporidium sp. & Cryptosporidium sp. \\
\hline P3 26 & C. baileyi & - & - \\
\hline A02 & C. meleagridis & - & - \\
\hline NS7 & C. baileyi & - & - \\
\hline SL1 & C. parvum & - & C. parvum \\
\hline NS6 & C. parvum & - & - \\
\hline NS4 & C. parvum & - & - \\
\hline P3 02 & C. baileyi & C. baileyi & C. baileyi \\
\hline P3 01 & C. baileyi & C. baileyi & C. baileyi \\
\hline P3 03 & C. baileyi & C. baileyi & C. baileyi \\
\hline P3 09 & C. baileyi & C. baileyi & C. baileyi \\
\hline P3 10 & C. baileyi & C. baileyi & C. baileyi \\
\hline P3 11 & C. baileyi & C. baileyi & C. baileyi \\
\hline P3 08 & C. baileyi & C. baileyi & C. baileyi \\
\hline P320 & C. baileyi & - & - \\
\hline P3 07 & C. baileyi & C. baileyi & C. baileyi \\
\hline P62 & C. baileyi & C. baileyi & C. baileyi \\
\hline P62FR & C. baileyi & C. baileyi & C. baileyi \\
\hline P68 Mal & C. baileyi & C. baileyi & C. baileyi \\
\hline SM9 & C. parvum & C. parvum & C. parvum \\
\hline $\mathrm{P} 21$ & C. baileyi & C. baileyi & - \\
\hline P30 & C. baileyi & C. baileyi & C. baileyi \\
\hline P3 04 & - & C. baileyi & C. baileyi \\
\hline P3 05 & - & C. baileyi & C. baileyi \\
\hline
\end{tabular}

only in humans (Abal-Fabeiro et al., 2013; Stensvold et al., 2014), also infects Brazilian chickens.

In previous works developed in our laboratory, we found nonspecific amplification of Eimeria and Isospora DNA using the nested PCR protocol described by Ryan et al. (2003), in DNA extracted from fecal samples from rabbits and canaries, respectively. Those findings motivated our comparison of Ryańs protocol with other nested PCR protocols for the detection of Cryptosporidium spp., but in the present study, no nonspecific amplification was observed in any of the protocols tested.

The forward primer used in the nested PCR of protocol 1 (Johnson et al., 1995) contains four substitutions in the annealing region with $C$. bovis, C. xiaoi, and Cryptosporidium ryanae sequences, which may explain the negative amplification obtained with the use of DNA from $C$. xiaoi-like genotype.

Despite the absence of statistical significance, protocol 1 (Johnson et al., 1995; Xiao et al., 1999, 2000; Jiang et al., 2005) detected slightly more positive samples than the other two protocols (Table 3). In contrast to the report of Mirhashemi et al. (2015), we found no difference in the positivity rates between protocols 2 (Ryan et al., 2003) and 3 (Xiao et al., 1999, 2000). Protocol 3 is the most widely used for the detection of Cryptosporidium. However, since the amplified fragments in the primary and secondary reactions are long, $\sim 1318$ bp and $\sim 835 \mathrm{bp}$, respectively, the efficiency of this method is supposedly inferior to those that amplify smaller fragments (Piyamongkol et al., 2003; Chakravorty et al., 2006). The difference in the size of amplicons justifies the results obtained by Mirhashemi et al. (2015) and the results observed in this experiment with the use of protocol 1 , which amplifies fragments of $\sim 848$ and $\sim 425 \mathrm{bp}$ in the primary and secondary reactions, respectively.

\section{Conclusion}

C. meleagridis was genotyped for the first time in Brazil, revealing the zoonotic subtype IIIgA23G3R1 in an intensive poultry production system. $C$. baileyi was the most frequently detected species in the feces of domestic chickens. Domestic chickens from extensive production systems may carry the zoonotic species $C$. parvum in feces. A genotype of Cryptosporidium genetically similar to two Cryptosporidium species of ruminants, C. xiaoi and C. bovis, was found in chickens from an extensive production system. No significant differences were observed among the three nested PCR protocols for the detection of Cryptosporidium spp.

\section{Acknowledgements}

We would like to thank the São Paulo Research Foundation (Fundação de Amparo à Pesquisa do Estado de São Paulo - FAPESP) for the financial support (2015/26334-8), the Coordination for the Improvement of Higher Education Personnel (Coordenação de Aperfeiçoamento de Pessoal de Nível Superior - CAPES) for a master's degree scholarship awarded to B.N. Santana and Daiane Mompean Romera for the assistance during the collection of fecal samples.

\section{References}

Abal-Fabeiro, J.L., Maside, X., Bello, X., Llovo, J., Bartolomé, C., 2013. Multilocus patterns of genetic variation across Cryptosporidium species suggest balancing selection at the gp60 locus. Mol. Ecol. 22, 4723-4732. http://dx.doi.org/10.1111/mec.12425.

Araújo, A.J., Kanamura, H.Y., Almeida, M.E., Gomes, A.H., Pinto, T.H., Da Silva, A., 2008. Genotypic identification of Cryptosporidium spp: isolated from HIV-infected patients and immunocompetent children of Súo Paulo, Brazil. Rev. Inst. Med. Trop. 50, $139-143$.

Bomfim, T.C.B., Gomes, R.S., Huber, F., Couto, M.C.M., 2013. The importance of poultry in environmental dissemination of Cryptosporidium spp. Open Vet. Sci. J. 7, 12-17.

Boom, R., Sol, C.J.A., Salimans, M.M.M., Jansen, C.L., Wetheim-van Dillen, P.M.E., Noordaa, J., 1990. Rapid and simple method for purification of nucleic acids. Clin. Microbiol. 28, 495-503.

Cama, V.A., Bern, C., Sulaiman, I.M., Gilman, R.H., Ticona, E., Vivar, A., Kawai, V., Vargas, D., Zhou, L., Xiao, L., 2003. Cryptosporidium species and genotypes in HIVpositive patients in Lima, Peru. J. Eukaryot. Microbiol. 50, 531-533. http://dx.doi. org $/ 10.1111 /$ j.1550-7408.2003.tb00620.x.

Cardozo, S.V., Teixeira Filho, W.L., Lopes, C.W.G., 2005. Transmissão experimental de Cryptosporidium baileyi (Apicomplexa: Cryptosporidiidae) isolado de frango de corteà codorna Japonesa (Coturnix japonica). Rev. Bras. Parasitol. Vet. 14, 119-124.

Chakravorty, S., Pathak, D., Dudeja, M., Haldar, S., Hanif, M., Tyagi, J.S., 2006. PCR amplification of shorter fragments from the devR (Rv3133c) gene significantly increases the sensitivity of tuberculosis diagnosis. FEMS Microbiol. Lett. 257, 306-311. http://dx.doi.org/10.1111/j.1574-6968.2006.00187.x.

Chalmers, R.M., Giles, M., 2010. Zoonotic cryptosporidiosis in the UK - challenges for control. J. Appl. Microbiol. 109, 1487-1497. http://dx.doi.org/10.1111/j.13652672.2010.04764.x.

Chelladurai, J.J., Clark, M.E., Kváč, M., Holubová, N., Khan, E., Stenger, B.L., Giddings, C.W., McEvoy, J., 2016. Cryptosporidium galli and novel Cryptosporidium avian genotype VI in North American red-winged blackbirds (Agelaius phoeniceus). Parasitol. Res. 115, 1901-1906. http://dx.doi.org/10.1007/s00436-016-4930-8.

Current, W.L., Upton, S.J., Haynes, T.B., 1986. The life cycle of Cryptosporidium baileyi n.s. (Apicomplexa: Cryptosporidiidae) infecting chickens. J. Protozool. 33, 289-296.

Gomes, R.S., Huber, F., Silva, S., Bomfim, C.B., 2012. Cryptosporidium spp. parasitize exotic birds that are commercialized in markets, commercial aviaries, and pet shops. Parasitol. Res. 110, 1363-1370. http://dx.doi.org/10.1007/s00436-011-2636-5.

Goodwin, M.A., Brown, J., Resurrecion, R.S., Smith, A.J., 1996. Respiratory coccidiosis (Cryptosporidium baileyi) among Northern Georgia broilers in one company. Avian Dis. 40, 572-575. http://dx.doi.org/10.2307/1592266.

Gorham, S.L., Mallinson, E.T., Snyder, D.B., Odor, E.M., 1987. Cryptosporidia in the bursa of Fabricius - a correlation with mortality rates in broiler chickens. Avian Pathol. 16, 205-211. http://dx.doi.org/10.1080/03079458708436369.

Hall, T., 1999. BioEdit: a user-friendly biological sequence alignment editor and analysis program for windows 95/98/NT. Nucleic Acids Symp. Ser. 41, 95-98.

Helmy, Y.A., Krücken, J., Abdelwhab, E.M., von Samson-Himmelstjerna, V., Hafez, H.M., 2017. Molecular diagnosis and characterization of Cryptosporidium spp. in turkeys and chickens in Germany reveals evidence for previously undetected parasite species. PLoS One 12 (6), e0177150.

Holubová, N., Sak, B., Horčičková, M., Hlásková, L., Květoňová, D., Menchaca, S., McEvoy, J., Kváč, M., 2016. Cryptosporidium avium n. sp. (Apicomplexa: cryptosporidiidae) in birds. Parasitol. Res. 115, 2243-2251. http://dx.doi.org/10.1007/ s00436-016-4967-8.

Huber, F., da Silva, S., Bomfim, T.C.B., Teixeira, K.R.S., Bello, A.R., 2007. Genotypic characterization and phylogenetic analysis of Cryptosporidium sp. from domestic animals in Brazil. Vet. Parasitol. 150, 65-74.

Jellison, K.L., Distel, D.L., Hemond, H.F., Schauer, D.B., 2004. Phylogenetic analysis of the hypervariable region of the 18S rRNA gene of Cryptosporidium oocysts in feces of Canada geese (Branta canadensis): evidence for five novel genotypes. Appl. Environ. Microbiol. 70, 452-458. http://dx.doi.org/10.1128/AEM.70.1.452-458.2004.

Jiang, J., Alderisio, K.A., Xiao, L., 2005. Distribution of Cryptosporidium genotypes in storm event water samples from three watersheds in New York. Appl. Environ. Microbiol. 71, 4446-4454. 
Johnson, D.W., Pieniazek, N.J., Griffin, D.W., Misener, L., Rose, J.B., 1995. Development of a PCR protocol for sensitive detection of Cryptosporidium oocysts in water samples. Appl. Environ. Microbiol. 61, 3849-3855.

Kumar, S., Stecher, G., Tamura, K., 2016. Molecular evolutionary genetics analysis version 7.0 for bigger datasets. Mol. Biol. Evol. 33, 1870-1874.

Laatamna, A.E., Holubová, N., Sak, B., Kvác, M., 2017. Cryptosporidium meleagridis and C. baileyi (Apicomplexa) in domestic and wild birds in Algeria. Folia Parasitol. 64, 018.

Landis, J.R., Koch, G.G., 1977. The measurement of observer agreement for categorical data. Biometrics 33, 159-174.

Majewska, A.C., Graczyk, T.K., Słodkowicz-Kowalska, A., Tamang, L., Jędrzejewski, S., Zduniak, P., Solarczyk, P., Nowosad, A., Nowosad, P., 2009. The role of free-ranging, captive, and domestic birds of Western Poland in environmental contamination with Cryptosporidium parvum oocysts and Giardia lamblia cysts. Parasitol. Res. 104, 1093-1099.

McLauchlin, J., Amar, C., Pedraza-Díaz, S., Nichols, G.L., 2000. Molecular epidemiological analysis of Cryptosporidium spp. in the United Kingdom: results of genotyping Cryptosporidium spp. in 1,705 fecal samples from humans and 105 fecal samples from livestock animals. J. Clin. Microbiol. 38, 3984-3990.

Meireles, M.V., Figueiredo, P.C., 1992. Isolamento e identificação de Cryptosporidium baileyi, current et alii, 1986 (Apicomplexa: Cryptosporidiidae) em frangos de corte. Rev. Bras. Parasitol. Vet. 1 (2), 125-130.

Meireles, M.V., Paulillo, A.C., Silva, G.S., Costa, A.J., Doretto Júnior, L., Machado, R.Z., 1998a. Infecção experimental por Cryptosporidium baileyi em aves de corte - aspectos clínicos, parasitológicos e zootécnicos. Rev. Bras. Parasitol. Vet. 7, 11-14.

Meireles, M.V., Paulillo, A.C., Silva, G.S., Costa, A.J., Luvizotto, M.C.R., Júnior, Doretto, Ávila, F.A., 1998b. Influência da infecção experimental com Cryptosporidium baileyi na resposta imune de frangos de corte vacinados contra a doença de Newcastle. Rev. Bras. Cienc. Vet. 5, 15-19.

Meireles, M.V., Paulillo, A.C., Silva, G.S., Luvizotto, M.C.R., Costa, A.J., Andreatti Filho, R.L., 1999. Experimental infection with Cryptosporidium baileyi in floor-pen raised broilers. Rev. Bras. Cienc. Avic. 1, 37-42.

Meireles, M.V., Soares, R.M., dos Santos, M.M.A.B., Gennari, S.M., 2006. Biological studies and molecular characterization of a Cryptosporidium isolate from ostriches (Struthio Camelus). J. Parasitol. 92, 623-626.

Mirhashemi, M.E., Zintl, A., Grant, T., Lucy, F.E., Mulcahy, G., De Waal, T., 2015. Comparison of diagnostic techniques for the detection of Cryptosporidium oocysts in animal samples. Exp. Parasitol. 151-152, 14-20. http://dx.doi.org/10.1016/j. exppara.2015.01.018.

Morgan, U.M., Monis, P.T., Xiao, L., Limor, J., Sulaiman, I., Raidal, S., O'Donoghue, P., Gasser, R., Murray, A., Fayer, R., Blagburn, B.L., Lal, A.A., Thompson, R.C.A., 2001. Molecular and phylogenetic characterisation of Cryptosporidium from birds. Int. J. Parasitol. 31, 289-296. http://dx.doi.org/10.1016/S0020-7519(00)00164-8.

Nakamura, A.A., Meireles, M.V., 2015. Cryptosporidium infections in birds - a review. Rev. Bras. Parasitol. Vet. 24, 253-267. http://dx.doi.org/10.1590/S198429612015063.

Nakamura, A.A., Simões, D.C., Antunes, R.G., da Silva, D.C., Meireles, M.V., 2009. Molecular characterization of Cryptosporidium spp. from fecal samples of birds kept in captivity in Brazil. Vet. Parasitol. 166, 47-51. http://dx.doi.org/10.1016/j.vetpar. 2009.07.033.

Nei, M., Kumar, S., 2000. Molecular Evolution and Phylogenetics. Oxford University Press, New York.

Ng, J., Pavlasek, I., Ryan, U., 2006. Identification of novel Cryptosporidium genotypes from avian hosts. Appl. Environ. Microbiol. 72, 7548-7553. http://dx.doi.org/10. 1128/AEM. 01352-06.

Oliveira, B.C.M., Ferrari, E.D., Panegossi, M.F.C., Nakamura, A.A., Corbucci, F.S., Nagata, W.B., Santos, B.M., Gomes, J.F., Meireles, M.V., Widmer, G., Bresciani, K.D.S., 2017. First description of Cryptosporidium parvum in carrier pigeons (Columba livia). Vet. Parasitol. 243, 148-150.

Piyamongkol, W., Bermudez, M.G., Harper, J.C., Wells, D., 2003. Detailed investigation of factors influencing amplification efficiency and allele drop-out in single cell PCR: implications for preimplantation genetic diagnosis. Mol. Hum. Reprod. 9, 411-420.

Qi, M., Wang, R., Ning, C., Li, X., Zhang, L., Jian, F., Sun, Y., Xiao, L., 2011. Cryptosporidium spp. in pet birds: genetic diversity and potential public health sig nificance. Exp. Parasitol. 128, 336-340.

Reboredo-Fernández, A., Ares-Mazás, E., Cacciò, S.M., Gómez-Couso, H., 2015. Occurrence of Giardia and Cryptosporidium in wild birds in galicia (Northwest Spain). Parasitology 146, 917-925.

Ryan, U., Xiao, L., Read, C., Zhou, L., Lal, A.A., Pavlasek, I., 2003. Identification of novel Cryptosporidium genotypes from the Czech Republic. Appl. Environ. Microbiol. 69, 4302-4307. http://dx.doi.org/10.1645/GE-74RI.

Ryan, U., Zahedi, A., Paparini, A., 2016. Cryptosporidium in humans and animals - a one health approach to prophylaxis. Parasite Immunol. 38, 535-547. http://dx.doi.org/ $10.1111 /$ pim. 12350

Ryan, U., 2010. Cryptosporidium in birds, fish and amphibians. Exp. Parasitol. 124, $113-120$.

Santos, M.M.A.B., Peiró, J.R., Meireles, M.V., 2005. Cryptosporidium infection in ostriches (Struthio camelus) in Brazil: clinical, morphological and molecular studies. Rev. Bras. Cienc. Avic. 7, 113-117.

Sergeant, E.S.G., 2017. Epitools Epidemiological Calculators. Ausvet Pty Ltd.. Available at: http://epitools.ausvet.com.au.

Slavin, D., 1955. Cryptosporidium meleagridis (sp.nov.). J. Comp. Pathol. 65, 262-266. http://dx.doi.org/10.1016/S0368-1742(55)80025-2.

Snyder, D.B., Current, W.L., Russek-Cohen, E., Gorham, S.L., Mallinson, E.T., Marquardt, W.W., Savage, P.K., 1988. Serologic incidence of Cryptosporidium in Delmarva broiler flocks. Poult. Sci. 67, 730-735. http://dx.doi.org/10.3382/ps.0670730.

Sréter, T., Varga, I., 2000. Cryptosporidiosis in birds - a review. Vet. Parasitol. 87, 261-279. http://dx.doi.org/10.1016/S0304-4017(99)00178-8.

Stensvold, C.R., Beser, J., Axen, C., Lebbad, M., 2014. High applicability of a novel method for gp60-based subtyping of Cryptosporidium meleagridis. J. Clin. Microbiol. 52, 2311-2319. http://dx.doi.org/10.1128/JCM.00598-14.

Sulaiman, I.M., Lal, A.A., Xiao, L., 2002. Molecular phylogeny and evolutionary relationships of Cryptosporidium parasites at the actin locus. J. Parasitol. 88, 388-394. http://dx.doi.org/10.1645/0022-3395(2002)088[0388:MPAERO]2.0. CO;2.

Thompson, J.D., Gibson, T.J., Plewniak, F., Jeanmougin, F., Higgins, D.G., 1997. The CLUSTAL X windows interface: flexible strategies for multiple sequence alignment aided by quality analysis tools. Nucleic Acids Res. 25, 4876-4882.

Wang, L., Xue, X., Li, J., Zhou, Q., Yu, Y., Du, A., 2014. Cryptosporidiosis in broiler chickens in Zhejiang Province, China: molecular characterization of oocysts detected in fecal samples. Parasite 21, 36. http://dx.doi.org/10.1051/parasite/2014035.

Xiao, L., Morgan, U.M., Limor, J., Escalante, A., Arrowood, M., Shulaw, W., Thompson, R.C.A., Fayer, R., Lal, A.A., 1999. Genetic diversity within Cryptosporidium parvum and related Cryptosporidium species. Appl. Environ. Microbiol. 65, 3386-3391.

Xiao, L., Alderisio, K., Limor, J., Royer, M., Lal, A.A., 2000. Identification of species and sources of Cryptosporidium oocysts in storm waters with a small-subunit rRNA-based diagnostic and genotyping tool. Appl. Environ. Microbiol. 66, 5492-5498.

Xiao, L., Bern, C., Limor, J., Sulaiman, I., Roberts, J., Checkley, W., Cabrera, L., Gilman, R.H., Lal, A.A., 2001. Identification of 5 types of Cryptosporidium parasites in children in Lima, Peru. J. Infect. Dis. 183, 492-497. http://dx.doi.org/10.1086/318090.

Yang, W., Chen, P., Villegas, E.N., Landy, R.B., Kanetsky, C., Cama, V., Dearen, T., Schultz, C.L., Orndorff, K.G., Prelewicz, G.J., Brown, M.H., Young, K.R., Xiao, L., 2008. Cryptosporidium source tracking in the Potomac river watershed. Appl. Environ. Microbiol. 74, 6495-6504. http://dx.doi.org/10.1128/AEM. 01345-08.

Zhou, L., Kassa, H., Tischler, M.L., Xiao, L., 2004. Host-adapted Cryptosporidium spp. in Canada geese (Branta canadensis). Appl. Environ. Microbiol. 70, 4211-4215. http:// dx.doi.org/10.1128/AEM.70.7.4211-4215.2004.

Zylan, K., Bailey, T., Smith, H.V., Silvanose, C., Kinne, J., Schuster, R.K., Hyland, K., 2008. An outbreak of cryptosporidiosis in a collection of Stone curlews (Burhinus oedicnemus) in Dubai. Avian Pathol. 37, 521-526. http://dx.doi.org/10.1080/ 03079450802357019. 